\title{
Relationship between Functional Movement Screen and Athletic Performance in Children Tennis Players
}

\author{
Suat Yıldız \\ Faculty of Sport Sciences, Manisa Celal Bayar University, Turkey
}

Copyright $(2018$ by authors, all rights reserved. Authors agree that this article remains permanently open access under the terms of the Creative Commons Attribution License 4.0 International License

\begin{abstract}
FMS is one of the test battery that is used very common recently. Asymmetries and limitations of the functional movement patterns could be detected with this test battery. Study's purpose was to evaluate the relationship between FMS and athletic performance parameters in prepubertal children. 28 male children voluntarily participated in the study (Age: $9.6 \pm 0.7$ years, Height: $134.1 \pm 6.8 \mathrm{~cm}$, Weight: $31.3 \pm 4.1 \mathrm{~kg}$, and Training Duration: $3.1 \pm 1.3$ years). In study's results, a very significant relationship was found between FMS and static and dynamic balance and flexibility and CMJ $(p<0.01)$. A significant relationship was found between FMS and agility and acceleration $(p<0.05)$. Athletic performance parameters may predict with FMS test battery in prepubertal children. After athletic performance predicted if the quality of functional movement patterns are improved next stages of development may increase children's tennis performance.
\end{abstract}

Keywords Tennis, FMS, Prepuberty, Athletic Performance

\section{Introduction}

Fundamental movement skills are the essential skills that should be improved until 10 years old and these skills are almost foundation for every sport [1-3]. While improving these fundamental movement skills some athletic abilities of the children should be neglected and they will be a basis for the future. In this way when the age of specialization comes children will have competencies for performing sport-specific movement skills easily. After 10 years old it's important to improve some athletic abilities such as agility, power, mobility, flexibility, speed, balance, coordination and there should be a continuation with respect to age as well as sport-specific skills [1-4].

Flexibility is described as an ability to move joint through its range of motion [5]. Also, flexibility is an ability that should be improved as much as needs of sport $[6,7]$. Mostly terms of flexibility and mobility are neither confused nor used for each other. Mobility expresses having enough range of motion to make a movement in movement pattern's itself and it's further than flexibility [8]. In children, mobility and flexibility are important skills that should be improved proper to stages of development and shouldn't be lost for the next stages [3]. Muscle imbalance is one of the main reasons for the injuries [5]. In Tennis, it's thought that one of the reasons for the injuries too [9]. If an athlete doesn't have competencies, athletes who compete in the ages groups will be under the serious risk of injury upon both upper and lower extremities [9-12].

Balance is an ability to place the center of gravity through the base of support [13]. Balance system continuously takes assistance from the structures of visual, vestibular, somatosensorial to maintain proper body position [14]. This ability is performed both static and dynamic and has a unique place for the sports performance [14]. Balance is used to evaluate various abilities [13]. There are various test to evaluate balance performance such as Single Leg Stance Test, Stork Test, Star Excursion Balance Test [15], Balance Error Scoring System Test, Y Balance Test [13].

Vertical jumping is accepted as a distinctive ability in the most of sports. Sports such as tennis, basketball, soccer, handball, volleyball that requires vertical force production as the result of applied force to the ground and due to common usage vertical jumping ability in these sports, this ability requires testing [16-22]. In a study previously done showed that hopping ability between 10-15 years increases with growth [23]. Evaluation of this performance is important for the athlete.

Acceleration is the first $10 \mathrm{~m}$ in the sprint $[24,25]$. Acceleration ability describes the rate of change of velocity or how quickly an athlete can change the velocity of motion [26]. Agility is the rapid body movements in response to stimulus and it includes reactiveness [27]. These two abilities are performed as complex in the tennis. The athlete performs acceleration-deceleration and change of direction proper to the way of the coming ball or not the 
change of direction. In jumping, skipping, hopping activities benefit from the stretch-shortening cycle and this ability improves with growth too [28].

It's needed a test battery that will evaluate and give an idea about performance parameters of the athlete about these described abilities. Athlete's mobility and stability, muscular strength and flexibility, coordination and balance levels could be evaluated with FMS test battery [8, 29]. FMS test battery recently has been very popular to predict different situations and abilities [30-33]

In a study, it's indicated that FMS could be an effective testing tool to evaluate stability and mobility levels of the children and adolescents between 10-17 years old [34]. In a study showed that FMS' individual pointing system could be a predictor to decide performance parameters of the athletes who compete in U16-U19 [35]. Another study indicated that FMS points could give information about physical performance [36]. Our study's purpose was the evaluation of the effectiveness of FMS to predict athletic performance parameters and to detect relationship between functional movement and athletic performance of children tennis players who are 10-12 years old.

\section{Materials and Methods}

\subsection{Subjects}

28 Healthy children tennis players voluntarily participated in the study (Age: $9.6 \pm 0.7$ years, Height: $134.1 \pm 6.8 \mathrm{~cm}$, Weight: $31.3 \pm 4.1 \mathrm{~kg}$, and Training Duration: $3.1 \pm 1.3$ years).

Participants warmed up according to Gelen's recommendations [37] just before athletic performance tests not before FMS test battery. The study was approved by the Human Research Ethics Committee of the University and required permissions were obtained from children's family. All stages of the study were done properly to the declaration of Helsinki.

\subsection{Measurement Procedure}

After FMS test, balance (static and dynamic), jumping (CMJ), acceleration (10 m sprint), flexibility (sit \& reach) and agility (T-test) test batteries was carried out by athletes. Performance tests were performed twice and the best result was accepted.

\subsection{Functional Movement Screen (FMS)}

FMS is a test battery that consists of 7 main and 3 clearance tests. In the test with respect to quality of movement, participants get point between 0-3. Participants would have $0-21$ points from 7 seven tests and maximum 3 points each.

Participants balance tests measured with Y Balance Test (dynamic) and Balance Error Scoring System (BESS) (Static). CMJ test was performed on a mat (Newtest 2000, Oulu, Finland) and flight and ground contact times took into consideration. Participant's Acceleration Tests were evaluated with a photocell system that is $10 \mathrm{~m}$ (Newtest 2000, Oulu, Finland). Participants lower body flexibility results were obtained from Sit and Reach Test (Takei Sci., Co., Ltd, DGTK-5403, and JP). Agility Test was measured with T-Test and photocell system was used to measure times (Newtest 2000, Oulu, Finland).

\subsection{Statistical Analysis}

SPSS was used for statistical analysis. All performance parameters and FMS points were correlated with each other and Pearson Correlation Test was used.

\section{Results}

In our study, there is a very significant correlation between FMS and Flexibility, CMJ, Dynamic and Static Balance $(p<0.01)$. Significant correlation found between FMS and speed, agility $(p<0.05)$.

Table 1. Corelation of FMS and athletic performance

\begin{tabular}{ccccccccc}
\hline & Flexibility & CMJ & $\mathbf{1 0}$ m speed & T- Test & $\begin{array}{c}\text { Dyn. Balance } \\
\text { Right }\end{array}$ & $\begin{array}{c}\text { Dyn. } \\
\text { Balance Left }\end{array}$ & Static Balance \\
\hline \multirow{2}{*}{ FMS } & Pearson Correlation &, $735^{* *}$ &, $570^{* *}$ &, $441^{*}$ &, $449^{*}$ &, $622^{* *}$ &, $700^{* *}$ &, $842^{* *}$ \\
\cline { 2 - 9 } & Sig. (2-tailed) &, 000 &, 002 &, 019 &, 017 &, 000 &, 000 &, 000 \\
\hline
\end{tabular}

**. Correlation is significant at the 0.01 level (2-tailed).

*. Correlation is significant at the 0.05 level (2-tailed). 


\section{Discussion}

In tennis evaluation of physical competencies is a need. While creating training programs for athletes it's necessary to have a starting point. By this way, physical competencies appropriately could be increased.

In FMS test battery with the Deep squat that requires vertically force production, potential performance outputs of vertical jumping ability could predict. In our study, a very significant correlation was found between FMS and vertical jumping $(p<0.01)$. The athlete has to have well both mobility and stability in the ankle, knee, and hip areas to perform CMJ continuously. This is important for not leaking of power output and maintaining the quality of movement during dynamic movement. In childhood and adolescent periods jumping performance improves [38]. One of the important parameters that affect CMJ performance is the stretch-shortening cycle that eccentric and concentric contractions occur one after the other. This ability could be improved with a planned and periodized programme in 10-12 years old children. Another parameter that affects vertical jumping performance is the ankle joint dorsiflexion that lets eccentric contraction of the calves at the wider degrees [39]. The athletes would be able to perform better movement patterns with an improvement in this ability. As the result tennis performance will be positively influenced. In our study, a very significant relationship was found between FMS and flexibility $(p<0.01)$. In a study, it's indicated that more elasticity in muscle-tendon units is related to weaker power outputs in prepubertal children [40]. For flexibility 6-11 ages is accepted important periods for the development of this ability [41]. Preventing this ability during this period is important to inhibit movement limitations of children. Due to this concern, FMS test battery could be used as a tool for evaluation of flexibility.

Other results of our study showed that a very significant relationship was found between FMS and static and dynamic balance. $(p<0.01)$ In FMS with Deep Squat, In-line Lunge and Hurdle Step Tests balance assessment can be possible on two leg stance, tandem position and one leg. It was indicated that if balance ability is improved lower body asymmetry would decrease [42]. Balance ability was also related to injuries [43]. Due to this, detection of the asymmetries would decrease the occurrence of the injuries. It could be detected that which parts of the body have asymmetry and which parts of the body would take place a problem for the athlete with FMS.

Lastly, in our study, the significant relationship was found between FMS and 10m sprint and agility $(p<0.05)$. Agility includes acceleration phase. These two abilities may benefit from each other. Basic factors that constitute speed are stride length and cadence [44]. During the acceleration phase, ground contact time is more [41]. In this phase, athlete applies more force to the ground with a wider degree. This situation requires more physical effort.
Hip, knee, ankle areas work coordinated together at the wider degree to produce force. In FMS test battery this acceleration ability could be evaluated with Hurdle Step test [8]. In this test, the athlete performs almost same movement pattern with acceleration and an implication could be obtained with respect to quality of movement. While running for the proper technique arms need to be used [44]. If the athlete can't use arm movements effectively and if there is any limitation it's thought that it would affect athlete's speed performance. In FMS, Shoulder Mobility Reaching Test makes possible to assess athletes' shoulder complex's movement capability. Agility includes deceleration, stop and reacceleration processes. During deceleration athlete benefits from eccentric contraction [26]. In In-line Lunge Test effectiveness of eccentric contraction is one of the abilities that is tested it means basically testing of deceleration [8]. Tennis is a sport that mainly requires improved acceleration and deceleration abilities. FMS test could give us an opportunity to assess athletic performances with functional movement pattern.

\section{Conclusions}

To obtain valid data from test battery about performance whole tests should be associated with each other. This test gives us an opportunity to see limitations and asymmetries as well as potential prediction of athletic performance. Tennis is performed with movement patterns just like other sports. Because of this, it's very helpful to see athlete's movement pattern's qualities that compete in underage categories. If there is any problem about pattern it would be corrected at that time, improved quality of movement pattern would cause the increase in athletic performance [32].

\section{REFERENCES}

[1] Balyi I, Way R, Higgs C. Long-Term Athlete Development: Human Kinetics; 2013.

[2] Bompa T, Carrera M. Conditioning Young Athletes: Human Kinetics; 2015.

[3] Lloyd RS, Oliver JL, Faigenbaum AD, Howard R, De Ste Croix MB, Williams CA, et al. Long-term athletic development- part 1: a pathway for all youth. J Strength Cond Res. 2015; 29(5):1439-50.

[4] Arabacı, R., R. Görgülü, and F. Çatıkkaș, Relationship between Agility, Speed, Reaction Time and Body Mass Index in Taekwondo Athletes. E-Journal of New World Sciences Academy, 2010. 5(2): p. 71-77.

[5] Clark M, Lucett S, Sutton BG, Medicine NAoS. NASM Essentials of Personal Fitness Training: Wolters Kluwer Health/Lippincott Williams \& Wilkins; 2012. 
[6] Gleim GW, McHugh MP. Flexibility and its effects on sports injury and performance. Sports Med. 1997;24(5):289-99.

[7] Dilber, A.O., et al., Erkek Futbolcularda 8 Haftalık Kor Antrenmanının Performansla İlgili Fiziksel Uygunluk Değişkenleri Üzerine Etkisi. CBÜ Beden Eğitimi ve Spor Bilimleri Dergisi, 2016. 11(2): p. 77-82

[8] Cook G. Movement: Functional Movement Systems: Screening, Assessment, Corrective Strategies: On Target Publications, LLC; 2010.

[9] Bylak J, Hutchinson MR. Common sports injuries in young tennis players. Sports Med. 1998;26(2):119-32.

[10] Ellenbecker TS, Pluim B, Vivier S, Sniteman C. Common Injuries in Tennis Players: Exercises to Address Muscular Imbalances and Reduce Injury Risk. Strength \& Conditioning Journal. 2009; 31(4):50-8

[11] Kibler WB, Chandler TJ. Range of motion in junior tennis players participating in an injury risk modification program. Journal of science and medicine in sport. 2003; 6(1):51-62.

[12] Kibler WB, Safran MR. Musculoskeletal injuries in the young tennis player. Clin Sports Med. 2000;19(4):781-92.

[13] Brachman A, Kamieniarz A, Michalska J, Pawlowski M, Slomka KJ, Juras G. Balance Training Programs in Athletes - a Systematic Review. J Hum Kinet. 2017; 58:45-64.

[14] Hrysomallis C. Balance ability and athletic performance. Sports Med. 2011; 41(3):221-32.

[15] Reiman MP, Manske, R.C. Functional Testing in Human Performance: İstanbul Tip Kitabevleri; 2018.

[16] Fernandez-Fernandez J, Ulbricht A, Ferrauti A. Fitness testing of tennis players: how valuable is it? $\mathrm{Br} \mathrm{J}$ Sports Med. 2014;48 Suppl 1:i22-31.

[17] Kruger K, Pilat C, Uckert K, Frech T, Mooren FC. Physical performance profile of handball players is related to playing position and playing class. J Strength Cond Res. 2014; 28(1):117-25.

[18] Rodriguez-Rosell D, Mora-Custodio R, Franco-Marquez F, Yanez-Garcia JM, Gonzalez-Badillo JJ. Traditional vs. Sport-Specific Vertical Jump Tests: Reliability, Validity, and Relationship with the Legs Strength and Sprint Performance in Adult and Teen Soccer and Basketball Players. J Strength Cond Res. 2017; 31(1):196-206.

[19] Sattler T, Sekulic D, Hadzic V, Uljevic O, Dervisevic E. Vertical jumping tests in volleyball: reliability, validity, and playing-position specifics. J Strength Cond Res. 2012; 26(6):1532-8

[20] Sheppard JM, Cronin JB, Gabbett TJ, McGuigan MR, Etxebarria N, Newton RU. Relative importance of strength, power, and anthropometric measures to jump performance of elite volleyball players. J Strength Cond Res. 2008; 22(3):758-65.

[21] Stolen T, Chamari K, Castagna C, Wisloff U. Physiology of soccer: an update. Sports Med. 2005;35(6):501-36.

[22] Ziv G, Lidor R. Physical attributes physiological characteristics, on-court performances and nutritional strategies of female and male basketball players. Sports Med. 2009; 39(7):547-68

[23] Lloyd RS, Oliver JL, Hughes MG, Williams CA. Age-related differences in the neural regulation of stretch-shortening cycle activities in male youths during maximal and sub-maximal hopping. J Electromyogr Kinesiol. 2012;22(1):37-43.

[24] Little T, Williams AG. Specificity of acceleration, maximum speed, and agility in professional soccer players. J Strength Cond Res. 2005; 19(1):76-8.

[25] Hewit J, Cronin J, Button C, Hume P. Understanding Deceleration in Sport2011. 47-52 p.

[26] Association NNSC, Dawes J, Roozen M. Developing Agility and Quickness: Human Kinetics 1; 2012.

[27] Sheppard JM, Young WB. Agility literature review: classifications, training and testing. J Sports Sci. 2006; 24(9):919-32.

[28] Radnor JM, Oliver JL, Waugh CM, Myer GD, Moore IS, Lloyd RS. The Influence of Growth and Maturation on Stretch-Shortening Cycle Function in Youth. Sports Med. 2018; 48(1):57-71.

[29] Yıldız S, Pınar S, Gelen E. Çocuk Tenisçilerde Fonksiyonel Antrenman: LAP Lambert Academic Publishing; 2017.

[30] Kiesel K, Plisky PJ, Voight ML. Can Serious Injury in Professional Football be predicted by a Preseason Functional Movement Screen? N Am J Sports Phys Ther. 2007; 2(3):147-58

[31] Bagherian S, Ghasempoor K, Rahnama N, Wikstrom EA The Effect of Core Stability Training on Functional Movement Patterns in Collegiate Athletes. J Sport Rehabil. 2018:1-22.

[32] Y1ldiz S. Relationship between Functional Movement Screen and Some Athletic Abilities in Karate Athletes. 2018. 2018;6(8):4

[33] Okada T, Huxel KC, Nesser TW. Relationship between Core Stability, Functional Movement, and Performance. The Journal of Strength \& Conditioning Research. 2011; 25(1):252-61.

[34] Abraham A, Sannasi R, Nair R. Normative values for the functional movement screentm in adolescent school aged children. International journal of sports physical therapy. 2015; 10(1):29-36

[35] Silva B, Clemente FM, Camoes M, Bezerra P. Functional Movement Screen Scores and Physical Performance among Youth Elite Soccer Players. Sports (Basel). 2017; $5(1)$

[36] Lloyd RS, Oliver JL, Radnor JM, Rhodes BC, Faigenbaum $\mathrm{AD}$, Myer GD. Relationships between functional movement screen scores, maturation and physical performance in young soccer players. J Sports Sci. 2015; 33(1):11-9.

[37] Gelen E. Acute effects of different warm-up methods on sprint slalom dribbling, and penalty kick performance in soccer players. J Strength Cond Res. 2010; 24(4):950-6. 
[38] Focke A, Strutzenberger G, Jekauc D, Worth A, Woll A, Schwameder H. Effects of age, sex and activity level on counter-movement jump performance in children and adolescents. Eur J Sport Sci. 2013; 13(5):518-26.

[39] Yun SJ, Kim MH, Weon JH, Kim Y, Jung SH, Kwon OY. Correlation between toe flexor strength and ankle dorsiflexion ROM during the countermovement jump. J Phys Ther Sci. 2016; 28(8):2241-4.

[40] Dotan R, Mitchell C, Cohen R, Klentrou P, Gabriel D, Falk B. Child-adult differences in muscle activation--a review. Pediatr Exerc Sci. 2012; 24(1):2-21.
[41] Joyce D, Lewindon D. High-Performance Training for Sports: Human Kinetics Publishers; 2014.

[42] Sannicandro I, Cofano G, Rosa RA, Piccinno A. Balance training exercises decrease lower-limb strength asymmetry in young tennis players. J Sports Sci Med. 2014; 13(2):397-402.

[43] Hrysomallis C. Relationship between balance ability, training and sports injury risk. Sports Med. 2007; 37(6):547-56.

[44] Association NSC, Jeffreys I. Developing Speed: Human Kinetics; 2013. 